weak mutton broth, and to have the oil in the morning as usual.

9th. Improving; mouth very sore; stools remarkably altered. Is said by her mother to have relished the broth with bread, and to have asked for meat, to have little fever in an evening, but to be very low at times; pulse 104; complexion clearer; tongue as yesterday. Ordered the following :-

IN Infus. Calumbo siijss; Tinct. Rhari, Tinct. Iodina, aa. jij. M. fiatque infusio; hujus capiat coch. am. plum bis in die hora 11 ma a.m. 4 taque, p.m.

12th. Proceeding favourably. Took meat yesterday, and slept well after it at night. Bowels very comfortable; tongue clean and moist; mouth still complained of ; pulse 94 ; desired to restrain her appetite for solids, to continue the infusion, and to have a small quantity of ol. ric. each morning.

14th. Gaining strength and colour; rode out this morning for an hour.

17 th. I have this day visited Miss W. for the last time, her mother having pro mised to take her into the country.

Remarks.-The preceling case is extracted as one of a favourable description, and coming under my notice at what may be termed the middle period, or second stage. Of the remedies used, local bloodletting, mercury, and iodine, more anon, when we review generally the treatment of infantile remittent fever.

June 18, 1835.

\section{MORBIDLY PROTRACTED SLEEP.}

\section{To the Editor of The LANCET.}

Sir, -In the last number of Tre LaNCET, Dr. Fosbroke of Ross bas detailed a case which he has entitled "Coma Somnolentum." Besides the difficulty that arises out of the use of a name of uncertain meaning without a definition, or a definition as perfect as our science will admit, I acknowledge that to me there is in Dr. Fosbroke's meaning considerable obscurity.

As to the name, which is of just so much importance as that it may enable us all to speak of the same thing, Dr. Fosbroke and Boerhaave, who, I trust, he will consider of sufficient authority as a nomenclator, understand by " coma somnolentum," a very different disease. For, whereas in Dr.Fosbroke's case, the "waters of the Wye" could not make the patient speak or open her eyes, we read in Bocrhaave "Coma Somnolentum verò vocatur ac definitur morbus in quo ægri somnum profundum habent, sine febre, in quo quamdiu excitantur, oculus aperiunt, vel ad interrogata respondent, \&c.

But we are ready to admit the difficulty of nosological nomenclature applied to the neuroses, a class of which we know so little, and, for that reason, do the more urge that our cases should be set down modestly at the future disposal of pathology. Your correspondent, however, has grouped together, or glanced at, a number of dismilar cases, either to the confusion of a confused subject, or to illustrate what he calls "Coma Somnolentum," and show the danger of bleerling and cupping, which are always elbowed to one side by a note of admiration!

Your correspondent seems to me to come pretty quickly to his conclusion,-a conclusion which may have been ground. ed upon circumstances not detailed, but which is not sufficiently warranted by a statement of the co-existence of a gastroenteric disturbance, or by the result of the treatment. I would further venture to say, that vascular turgidity has been the cause of morbidly protracted sle $e$, as profound as it was with Mutlow. I met with the following case last summer.

Case.--On the 1st of August last I saw Mary Collins, aged nineteen, of plethoric habit, who was then, to all appearance, enjoying a sound and comfortable sleepl. Early next morning they had vainly tried to awaken her, and now at two in the afternoon she was equally insensible to outward impressions. 'The day and night but one preceding, she had slept profoundly in the same manner. When $I$ saw her she was breathing regularly, without stertor; there was not, and had not been, any convulsion; the limbs were relaxed, and she had all the appearance of enjoying natural sleep. Pinching or puncturing the skin, strong and pungent scents, shouting in the ear, were all alike unavailing towards arousing the patient. On touching the eyeball, or applying a candle towards it, it turned slightly down towards its waking position, but soon again was carried upwards and inwards, in whick position it remained. The pupil did not contract before the candlelight. The pulse was full and firm, 90 in the minute; the respiration natural, regular, and without stertor. The feet, as high as the ankles, were icy cold.

Mustard poultices were applied to the feet, and leeches to the neck. As sonn as the leeches had filled, she awoke as if from a natural sleep, without struggle or convulsion. About a twelvemonth before, this 
girl had several similar attacks, for which she was treated by Mr. Pritchard at our dispensary, and relieved by the establishment of the menstrual secretion, which, up to that time, had not been accomplished. For a couple of months preceding these last attacks she had not menstruated, and for two or three days she had been drowsy, and complaining of slight headach. Her friends describe her attacks as commencing with drowsiness, and advancing gradually to profound sleep. Her longest sleep has been six-and-thirty hours. My patient, on the lay following my first visit, was seized in a similar way, but on this occasion the sleep continued only three hours, and then terminated in an epileptic fit, from which she was recovered by a bleeding of eighteen ounces. The next attack, two days after, was one of common hysteria. At this time she had a blister applied to the hypogastrium, and was taking aloetic pills. The menstrual secretion appeared in a few days after; she had no later attack, and has continued in the enjoyment of good health. I am, Sir, your obedient servant,

W. Travers Cox, M.B., Member of the College of Plyysicians.

Great Yarmouth, June 18, 1835.

\section{CONCENTRATED INFUSIONS.}

\section{To the Editor of The LanceT.}

Sra,-In two numbers of your excellent publication there have appeared the remarks of two different correspondents, relative to the purity of the mode of preparation of many articles in the Pharmacopoia by druggists an 1 manufacturers generally. Among the preparations alluded to, one of the most prominent was the concentrated infusions, and the remarks in favom of these, in the latter communication, appear to me to be so very erroneous and so well calculated to mislead, that I cannot resist the inclination to offer a reply.

For the last eight years $I$ have been actively and extensively engaged in the study and operations of pharmacy, and have had occasion during that time to devote particular attention to the different proccsses for making the concentrated essences. Your correspondent, with the best motives I doubt not, states that the forms given by the Pharmacopoia for making infusions ought to be completely superseded by the superior convenience of the concentrated, which, with the exception of Inf. Sennæ, he praises in very high terms. Now, sir, so far from this being just, I firmly believe that the Inf. Sennæ is the only one of them which is good for anything at all. I think the reasons I subjoin will bear me out in this opinion.

I have cause to know from personal experience that almost the whole of the bitter concentrated infusions, as usually prepared, have their flavour given them, not by the respective drugs as is professed, but from the bitter principle extracted from quassia, and termed by Dr. Thomson quassin, which it is well known can be completely obtained by spirit and water, and which, more or less diluted, with different adjuncts to form a colour, is, as 1 have just said, the basis of the above-mentioned medical agents. With regard to the infusions of orange-peel and gentian, I can only say that the diluted product obtained from any sample of the strong article that $I$ have ever yet seen, has been totally different in appearance, taste, and smell, from the product obtained in the usual manner, being infinitely less pungent and grateful. Indeed it must be evident to any person who has devosed the least attention to the subject, that decoction will render any substance totally inert the active principles of which are volatile, or have any portion of extractive matter: one trial will speedily convince anybody that the bitter taste also is almost entirely lost by long coction. Inf. Sennx Concent. also, as commonly made, by boiling the leaves, is not of much worth, but if pre. pared by first forming a proportionately strong infusion, pressing it, adding a sufficiency of spirit to precipitate the mucilaginous matter, and, lastly, evaporating this product slowly in a water-bath to the just proportion, an article may be produced which will not deposit its cathartine, and which will possess a similar purgative effect to the infusion made in accordance with the Pharmacopœia.

I should not have ventured, sir, to trouble you with these remarks, had I not been apprized of the increasing circulation of the preparations in question, which I well know would not be the case if the medical profession were properly informed of their nerits. I have the honour to be, sir, your most obedient,

Pharmaceutical Assistant to the St. A.try-le-bone Infirmary. 